\title{
PEDIOCOCCUS SPECIES AND RELATED BACTERIA FOUND IN FERMENTED FOODS AND RELATED MATERIALS IN THAILAND
}

\author{
SOMBOON TANASUPAWAT AND WIWUT DAENGSUBHA* \\ Department of Microbiology, \\ Faculty of Pharmaceutical Science, Chulalongkorn University, Bangkok, Thailand \\ *Faculty of Science, Kasetsart University, Bangkok, Thailand
}

(Received November 14, 1983)

\begin{abstract}
Tetrad-forming cocci were isolated from 17 kinds of fermented fish, meat, vegetables, and other materials in Thailand. Out of 58 strains identified, 22 were Pediococcus pentosaceus Mees, 2 were Pedicoccus acidilactici Lindner, 26 were Pediococcus halophilus Mees, 4 were Pediococcus sp., and 4 were "Tetracoccus" sp. They were widely distributed in fermented products in Thailand, and play roles in souring and ripening.
\end{abstract}

The tetrad-forming bacteria mainly described as Pediococcus strains are found in a wide variety of beverages and fermented foods. These bacteria produce lactic acid from sugars. Spoilage of beer by such bacteria is reported (1). On the other hand, they play important roles in souring and ripening fermented foods; cucumber pickles $(2,3)$, shoyu (soy-sauce) $(4,5)$, miso (fermented soy bean paste) (6), nam-pla (fermented fish sauce in Thailand) (7), and burong dalag (fermented fish in the Philippines) (8). A great many fermented fish, meat, and vegetable foods are known in Thailand $(9,10)$, but little has been reported on the microorganisms involved. This paper deals with the identification of Pediococcus strains and related bacteria isolated mainly from these fermented foods.

\section{MATERIALS AND METHODS}

Isolation of bacteria. The tetrad-forming bacteria were isolated from the fermented foods obtained at the markets in Thailand, and from horse urine and animal feces by agar plate culture after 3 to 5 days' incubation at $30^{\circ}$. The medium $\left(\mathrm{GYP}-\mathrm{CaCO}_{3}\right)$ was composed of $10.0 \mathrm{~g}$, glucose; $10.0 \mathrm{~g}$, yeast extract (Difco); $10.0 \mathrm{~g}$, peptone (Difco); $10.0 \mathrm{~g}, \mathrm{CaCO}_{3} ; 12.0 \mathrm{~g}$, agar; and $1,000 \mathrm{ml}$, distilled

Address reprint requests to: Mr. Somboon Tanasupawat, Department of Microbiology, Faculty of Pharmaceutical Science, Chulalongkorn University, Bangkok 10500, Thailand. 


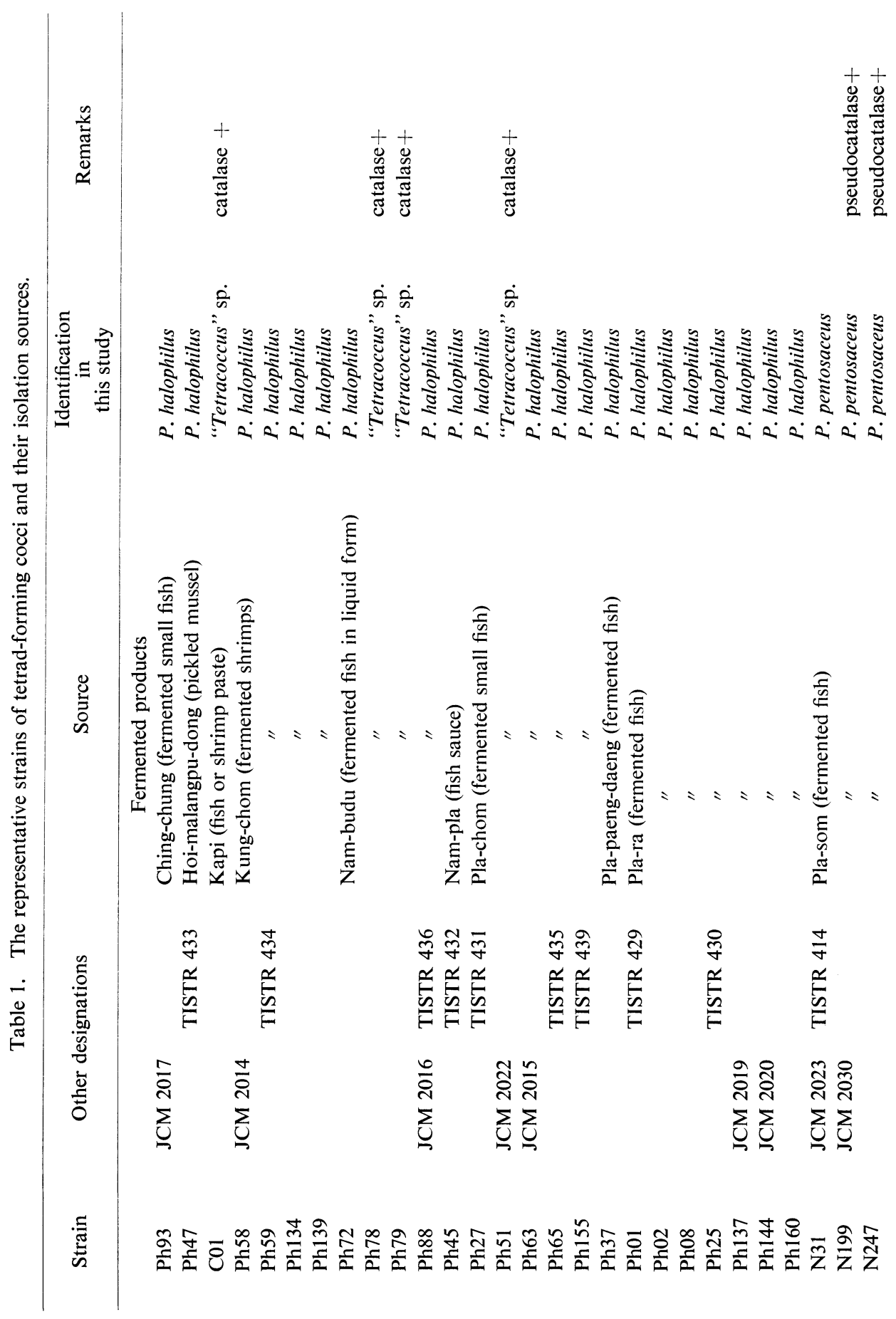



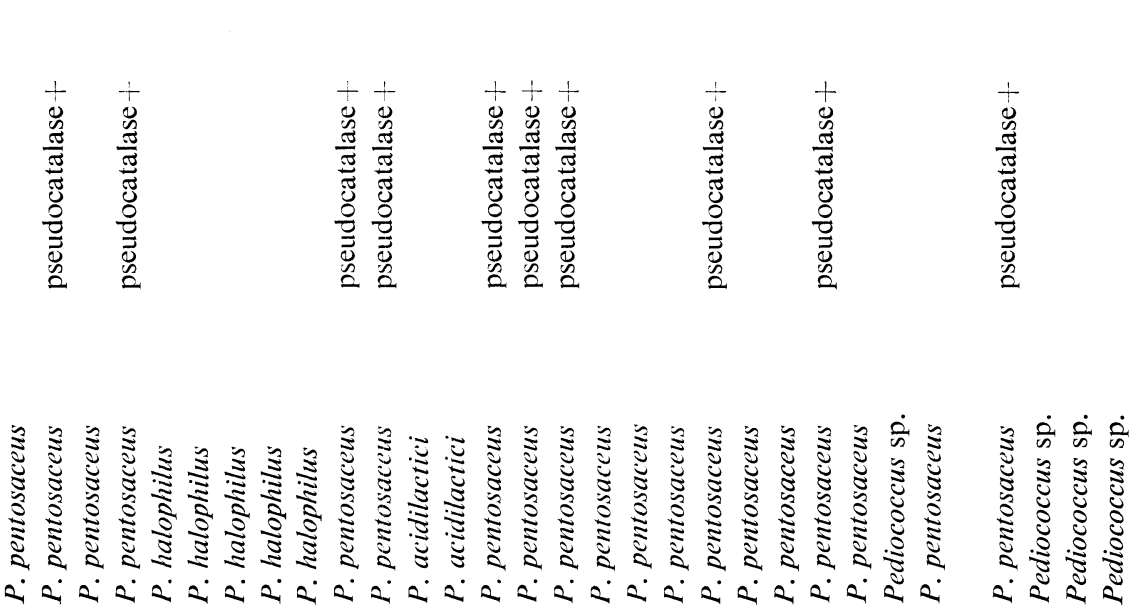

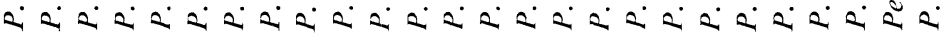

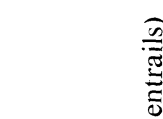
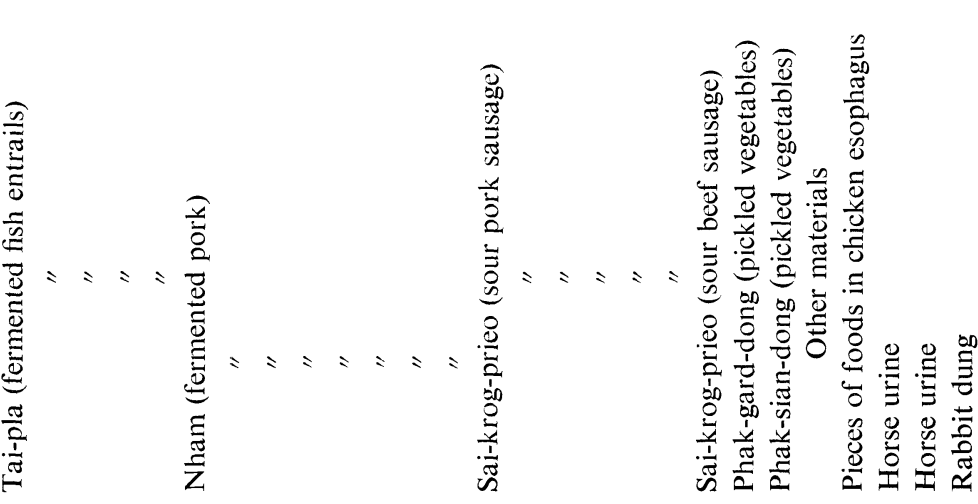

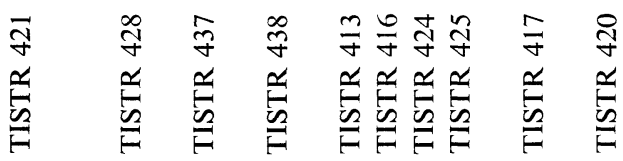

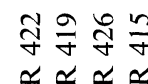

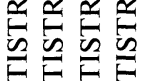

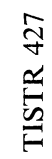

ธิ่

$\begin{array}{ll}\overrightarrow{0} & \infty \\ & \sum \\ 0 & 0\end{array}$

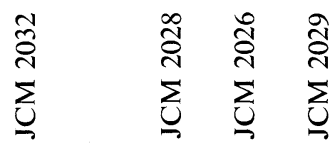

$\sum_{0} \sum_{0} \sum_{0}$

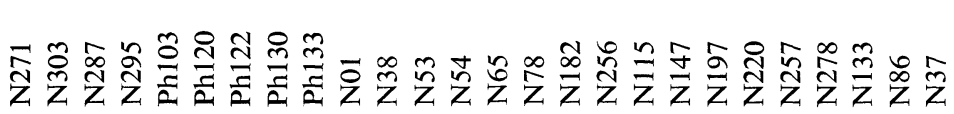


Table 2. Reference strains received from culture collections.

\begin{tabular}{|c|c|}
\hline Species & Strain designations \\
\hline Pediococcus acidilactici & ATCC 8042 \\
\hline Pediococcus acidilactici & ATCC 8081 \\
\hline "Pediococcus cerevisiae" & TISTR $335 \longleftarrow$ UQM 786 \\
\hline Pediococcus halophilus & TUA Ps $033 \longleftarrow$ NISL 7127 \\
\hline Pediococcus halophilus & TISTR $333 \longleftarrow$ DMKU B-120 \\
\hline Pediococcus pentosaceus & TUA Pc. \\
\hline "Pediococcus soyae" & TISTR $72 \longleftarrow$ IAM 1688 \\
\hline "Pediococcus urinae-equi" & TISTR 394๘IAM 1684 \\
\hline "Tetracoccus soyae" & TISTR $395 \longleftarrow$ TUA F-2 \\
\hline Leuconostoc mesenteroides & TISTR $53 \longleftarrow$ ATCC 10830 \\
\hline
\end{tabular}

ATCC, American Type Culture Collection, Rockville, Maryland, U.S.A. DMKU, Department of Microbiology, Kesetsart University, Bangkok, Thailand. IAM, Institute of Applied Microbiology, University of Tokyo, Tokyo, Japan. IFO, Institute for Fermentation, Osaka, Japan. NISL, Noda Industrial Science Laboratory, Noda, Chiba, Japan. TISTR, Thailand Institute of Scientific and Technological Research, Bangkok, Thailand. TUA, Tokyo University of Agriculture, Tokyo, Japan. UQM, Department of Microbiology, University of Queensland, Brisbane, Australia.

water; adjusted to $\mathrm{pH} 6.8$. For the isolation of halophilic strains, $50.0 \mathrm{~g}$ of $\mathrm{NaCl}$ was added to $1,000 \mathrm{ml}$ of $\mathrm{GYP}-\mathrm{CaCO}_{3}$ agar medium. Acid-forming bacteria were detected by the formation of colonies with clear zone dissolving $\mathrm{CaCO}_{3}$. As colonies appeared they were stabbed in $\mathrm{GYP}-\mathrm{CaCO}_{3}$ agar, and tetrad-forming bacteria were observed microscopically. Throughout the study, no anaerobic culture technique was employed for the isolation. Working cultures were maintained on GYP-sodium acetate-mineral salts broth composed of $10.0 \mathrm{~g}$, glucose; $10.0 \mathrm{~g}$, yeast extract (Difco); $10.0 \mathrm{~g}$, peptone (Difco), $10.0 \mathrm{~g}$, sodium acetate; $200 \mathrm{mg}, \mathrm{MgSO}_{4} \cdot 7 \mathrm{H}_{2} \mathrm{O} ; 10 \mathrm{mg}, \mathrm{MnSO}_{4} \cdot 4 \mathrm{H}_{2} \mathrm{O} ; 10 \mathrm{mg}, \mathrm{FeSO}_{4} \cdot 7 \mathrm{H}_{2} \mathrm{O}$; $10 \mathrm{mg}, \mathrm{NaCl}$; and $1,000 \mathrm{ml}$, distilled water; adjusted to $\mathrm{pH} 6.8$. For the halophilic strains, $50.0 \mathrm{~g}$ of $\mathrm{NaCl}$ was added to $1,000 \mathrm{ml}$ of GYP-sodium acetatemineral salts broth. The cultures were maintained by stabbing into GYP-CaCO agar and by lyophilization, and preserved at $4^{\circ}$. Names of samples in Thai are mainly cited from the references $(9,10)$, and difficulties are encountered in translation of Thai into English because some foods are produced in the limited local provinces and the processes are obscure.

Bacterial cultures. A total of 68 representative strains were used in this study. Strain designations and sources are shown in Tables 1 and 2. Named strains received from the culture collections were used as reference strains. Names which are not on the Approved Lists of Bacterial Names, 1980 (11) are enclosed in quotation marks.

Identification methods.

Morphological characteristics. Cell form, cell size, cell arrangement, and gram 
stain were observed on the cells grown on GYP agar plate after 3 to 5 days' incubation at $30^{\circ}$. Hucker's modification was employed for gram stain (12). Motility was examined by the appearance of the stab culture in semi-solid medium composed of $10.0 \mathrm{~g}$, glucose; $5.0 \mathrm{~g}$, beef extract; $5.0 \mathrm{~g}$, yeast extract (Difco); $0.5 \mathrm{ml}$, Tween $80 ; 0.04$ g, Bromocresol Purple (B.C.P.); $1.5 \mathrm{~g}$, agar; and 1,000 ml, distilled water; adjusted to $\mathrm{pH} 6.8$ (13). Spore formation was observed in a gram stained specimen.

Cultural characteristics. The colonial appearance was observed by the use of GYP agar plate after 1,3 , and 5 days' incubation at $30^{\circ}$. Turbidity and final $\mathrm{pH}$ of broth culture were observed by using GYP-sodium acetate-mineral salts broth.

Production of acid from sugars. Medium composed of $4.0 \mathrm{~g}$, yeast extract (Difco); $5.0 \mathrm{~g}$, peptone (Difco); $5.0 \mathrm{~g}$, sugar; $200 \mathrm{mg}, \mathrm{MgSO}_{4} \cdot 7 \mathrm{H}_{2} \mathrm{O} ; 10 \mathrm{mg}$, $\mathrm{MnSO}_{4} \cdot 4 \mathrm{H}_{2} \mathrm{O} ; 10 \mathrm{mg}, \mathrm{FeSO}_{4} \cdot 7 \mathrm{H}_{2} \mathrm{O} ; 10 \mathrm{mg}, \mathrm{NaCl}$; and $1,000 \mathrm{ml}$, distilled water; adjusted to $\mathrm{pH} 6.8$; and colored with Bromocresol Purple, was used to test for the production of acid from sugars. After 3 to 5 days' incubation, the change of the indicator was recorded. In some cases acid produced in $3 \mathrm{ml}$ of broth was titrated with $0.05 \mathrm{~N} \mathrm{NaOH}$. Twenty-two sugars were employed. For halophilic bacteria, $50.0 \mathrm{~g}$ of $\mathrm{NaCl}$ was added to $1,000 \mathrm{ml}$ of basal medium, and for the "Pediococcus urinae-equi" and related strains, the $\mathrm{pH}$ was adjusted to 7.2. Production of gas from glucose was tested by the method of GIBSON and ABD-EL-MALEK (14). Identification of lactic acid was determined by the method of DAwes et al. (15). Fermentation products from glucose were analysed by the method of Fehling and Lieman (16) to decide the type of lactic acid fermentation. Optical isomers of lactic acid were determined by the method of OKADA et al. (17).

Splitting of hydrogen peroxide. The production of catalase and pseudocatalase involves the splitting of hydrogen peroxide. The strains were cultivated on GYP agar plate containing $0.05,1.0$ or $2.0 \mathrm{~g}$ of glucose, and on YTG agar medium composed of $0.5 \mathrm{~g}$, glucose; $10.0 \mathrm{~g}$, Tryptone (Difco); $5.0 \mathrm{~g}$, yeast extract (Difco); $5.0 \mathrm{~g}, \mathrm{NaCl} ; 2.0 \mathrm{~g}, \mathrm{~K}_{2} \mathrm{HPO}_{4} \cdot 3 \mathrm{H}_{2} \mathrm{O} ; 15.0 \mathrm{~g}$, agar; and $1,000 \mathrm{ml}$, distilled water (18). After 1 and 3 days' incubation at $30^{\circ}$, a $3 \%$ solution of hydrogen peroxide was flooded over the colonies appearing on the agar plates, and the bubbling of gas was observed. The result was confirmed by the benzidine test (19). When both hydrogen peroxide splitting activity and the benzidine test were positive, the culture was assumed to be catalase positive. When hydrogen peroxide splitting activity was positive and the benzidine test was negative, the culture was assumed to be catalase negative but pseudocatalase positive. The activity of the culture was also tested on heated blood agar.

Biochemical characteristics. The following biochemical characteristics were tested by the methods described in the references: Reaction to litmus milk and hydrolysis of gelatin (16); hydrolysis of aesculin and hippurate (20), hydrolysis of arginine (21), the cleavage of glucose (22), nitrate reduction (16); reduction of 
tellurite, production of indole, MR-test, V-P reaction, utilization of citrate on Simmon citrate agar (23); slime formation on SYP medium composed of $10.0 \mathrm{~g}$, sucrose; $10.0 \mathrm{~g}$, yeast extract (Difco); $10.0 \mathrm{~g}$, peptone (Difco); $15.0 \mathrm{~g}$, agar; and $1,000 \mathrm{ml}$, distilled water; and oxidase test (24). Tolerance to Teepol was tested by the growth in GYP-sodium acetate-mineral salts medium containing $0.01,0.02$, or $0.05 \%$ Teepol, and by the growth in GYP-sodium acetate-mineral salts medium containing $8 \%$ of ethanol, and observed after 3 to 7 days' incubation at $30^{\circ}$.

Physiological characteristics. The relation to oxygen was tested by growth in semi-solid agar (13). The relation to temperature was tested by growth in GYP-sodium acetate-mineral salts broth incubated at $20^{\circ}, 30^{\circ}, 37^{\circ}, 40^{\circ}, 42^{\circ}, 48^{\circ}$, and $50^{\circ}$ for 3, 5 and 7 days. Effect of starting $\mathrm{pH}$ was detected by growth in GYPsodium acetate-mineral salts broth adjusted to an initial $\mathrm{pH}$ of 3.7, 4.5, 5.0, 6.7, 7.0, 7.4, 8.2, 8.6, 9.0, or 9.2 with $1 \mathrm{~N} \mathrm{HCl}$ and $1 \mathrm{~N} \mathrm{NaOH.} \mathrm{Halophilic} \mathrm{or} \mathrm{halotoler-}$ ant characteristics were determined by the growth in GYP-sodium acetate-mineral salts broth containing $0,2.0,4.0,6.0,8.0,10.0,12.0,14.0,16.0,18.0,20.0$, or $22.0 \%$ of $\mathrm{NaCl}$, and recorded after 3,5 , and 7 days at $30^{\circ}$. When the strains grew well in the presence of $\mathrm{NaCl}$ ranging from 4 to $12 \%$ and even at $18 \%$ of $\mathrm{NaCl}$, these were termed to be halophilic. These strains are considered to require $\mathrm{NaCl}$ for growth. When the strains grew in the absence of $\mathrm{NaCl}$ but grew even at $18 \% \mathrm{NaCl}$, those were termed to be halotolerant. These strains are considered not to require $\mathrm{NaCl}$ for growth.

\section{RESULTS}

The tetrad-forming bacteria isolated, including the strains received from the culture collections, were divided into two major groups. Out of 67 strains, 62 strains were catalase negative and 5 strains were catalase positive. The strains tested produced cocci forms and occurred in tetrads, in pairs, and rarely singly. Cell size was approximately 0.4 to $1.0 \mu \mathrm{m}$ in diameter. They were all gram positive, non-motile, and non-sporing. White, raised, and circular colonies appeared on GYP agar plate. Filiform growth was observed along stab lines on stab cultures.

In general, the catalase negative strains produced acid from a larger number of sugars than catalase positive strains did. The acidity of halophilic, catalase negative strains and catalase positive strains were much less than those of nonhalophilic, catalase negative strains as shown in Tables 3 and 4 . The main fermentation product from glucose by the isolates was lactic acid, and the production ratio of lactic acid to consumed glucose ranged from 75.10 to $99.74 \%$, except for Leuconostoc mesenteroides TISTR $53(55.50 \%)$ as shown in Table 5. On the basis of the results, the type of lactic acid fermentation was homotype. Further, $\mathrm{DL}+\mathrm{D}$ isomers were produced by strains $\mathrm{N} 78$ and $\mathrm{N} 86$; and $\mathrm{DL}+\mathrm{L}$ by the strains N53 and Ph01. Although the isolates were divided into the two major 
Table 3. Acidity produced by the pseudocatalase positive and pseudocatalase negative pediococci in sugar media.

\begin{tabular}{|c|c|c|c|c|c|c|c|c|c|}
\hline \multirow[b]{2}{*}{ Strain } & \multirow[b]{2}{*}{ Days } & \multicolumn{8}{|c|}{ Acidity $^{a}$} \\
\hline & & 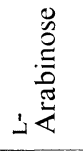 & 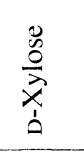 & 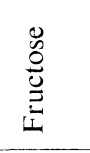 & 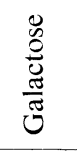 & 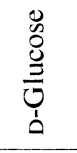 & 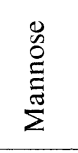 & $\begin{array}{l}0 \\
\ddot{0} \\
\stackrel{\Xi}{0} \\
\tilde{n}\end{array}$ & 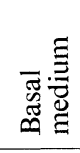 \\
\hline \multirow[t]{2}{*}{ N01 } & 3 & 0 & 0.05 & 1.00 & 2.60 & 2.40 & 1.40 & 1.80 & 0 \\
\hline & 7 & 0.05 & 0.05 & 2.40 & 2.90 & 2.90 & 1.90 & 2.20 & 0 \\
\hline \multirow[t]{2}{*}{ N31 } & 3 & 0.05 & 0.05 & 0.90 & 0 & 1.80 & 1.90 & 1.30 & 0 \\
\hline & 7 & 0.05 & 0.05 & 1.70 & 0 & 2.40 & 2.50 & 2.60 & 0 \\
\hline \multirow[t]{2}{*}{ N38 } & 3 & 3.60 & 2.40 & 2.60 & 2.20 & 3.00 & 3.00 & 0 & 0 \\
\hline & 7 & 3.55 & 2.90 & 2.90 & 2.50 & 2.95 & 3.10 & 0 & 0 \\
\hline \multirow[t]{2}{*}{ N53 } & 3 & 3.40 & 2.50 & 1.90 & 2.10 & 2.20 & 2.65 & 0 & 0 \\
\hline & 7 & 3.60 & 3.30 & 2.95 & 2.70 & 3.00 & 3.00 & 0 & 0 \\
\hline \multirow[t]{2}{*}{ N256 } & 3 & 3.60 & 0 & 2.70 & 2.80 & 2.70 & 2.40 & 0 & 0 \\
\hline & 7 & 3.80 & 0 & 3.20 & 3.00 & 2.90 & 3.00 & 0 & 0 \\
\hline \multirow[t]{2}{*}{ N271 } & 3 & 0.05 & 0.10 & 0.90 & 0.10 & 2.40 & 2.10 & 0.05 & 0 \\
\hline & 7 & 0.05 & 0.05 & 1.90 & 0.10 & 2.60 & 2.50 & 0.05 & 0 \\
\hline \multirow[t]{2}{*}{ N295 } & 3 & 0.05 & 0.05 & 2.30 & 3.20 & 3.10 & 3.00 & 3.20 & 0 \\
\hline & 7 & 0.05 & 0.05 & 2.60 & 3.10 & 3.10 & 3.20 & 3.40 & 0 \\
\hline
\end{tabular}

a Acidity is expressed as $\mathrm{ml}$ of $1 \mathrm{~N} / 20 \mathrm{NaOH}$ consumed to neutralize $3 \mathrm{ml}$ of culture broth incubated for 3 and 7 days.

Basal medium, free sugar.

Table 4. Acidity produced by the halophilic pediococci and the catalase positive tetracocci in sugar media.

\begin{tabular}{|c|c|c|c|c|c|c|c|c|c|}
\hline \multirow[b]{2}{*}{ Strain } & \multirow[b]{2}{*}{ Days } & \multicolumn{8}{|c|}{ Acidity $^{a}$} \\
\hline & & 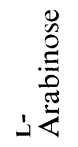 & $\begin{array}{l}\frac{0}{0} \\
\frac{0}{\lambda} \\
\dot{x} \\
\dot{0}\end{array}$ & 苞 & $\begin{array}{l}0 \\
0 \\
\frac{0}{0} \\
\frac{\pi}{\pi} \\
0\end{array}$ & 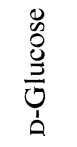 & $\begin{array}{l}0 \\
0 \\
\vdots \\
\vdots \\
\vdots\end{array}$ & 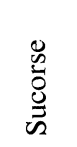 & 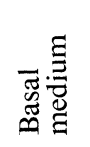 \\
\hline \multirow[t]{2}{*}{$\mathrm{Ph} 25$} & 3 & 0.25 & 0.20 & 0.20 & 0.20 & 0.25 & 0.20 & 0.10 & 0.10 \\
\hline & 7 & 0.30 & 0.20 & 0.30 & 0.25 & 0.30 & 0.25 & 0.20 & NT \\
\hline \multirow[t]{2}{*}{$\mathrm{Ph} 27$} & 3 & 0.15 & 0.20 & 0.25 & 0.20 & 0.25 & 0.20 & 0.20 & 0.10 \\
\hline & 7 & 0.20 & 0.25 & 0.30 & 0.25 & 0.25 & 0.30 & 0.25 & NT \\
\hline \multirow[t]{2}{*}{$\mathrm{Ph} 45$} & 3 & 0.05 & 0.10 & 0.40 & 0.40 & 0.40 & 0.40 & 0.10 & 0 \\
\hline & 7 & 0 & 0.10 & 0.45 & 0.45 & 0.60 & 0.50 & 0.25 & NT \\
\hline \multirow[t]{2}{*}{$\mathrm{Ph} 51$} & 3 & 0 & 0 & 0.50 & 0 & 0.60 & 0 & 0 & 0 \\
\hline & 7 & 0 & 0 & 0.80 & 0 & 0.90 & 0 & 0 & 0 \\
\hline \multirow[t]{2}{*}{ Ph79 } & 3 & 0 & 0 & 0.70 & 0 & 0.50 & 0 & 0 & 0 \\
\hline & 7 & 0 & 0 & 0.70 & 0 & 0.80 & 0 & 0 & 0 \\
\hline \multirow[t]{2}{*}{ TUA Ps033 } & 3 & 0 & 0.05 & 0.30 & 0.35 & 0.40 & 0.40 & NT & NT \\
\hline & 7 & 0 & 0.05 & 0.35 & 0.35 & 0.45 & 0.45 & 0.15 & 0 \\
\hline
\end{tabular}

a Acidity is expressed as $\mathrm{ml}$ of $1 \mathrm{~N} / 20 \mathrm{NaOH}$ consumed to neutralize $3 \mathrm{ml}$ of culture broth incubated for 3 and 7 days.

Basal medium, free sugar; NT, not tested. 
Table 5. The production ratio of lactic acid to consumed glucose and optical isomers of lactic acid of the representative strains.

\begin{tabular}{lcccc}
\hline Strain & $\begin{array}{c}\text { Consumed } \\
\text { glucose } \\
(\mathrm{mg} / \mathrm{ml})\end{array}$ & $\begin{array}{c}\text { Lactic acid } \\
\text { produced } \\
(\mathrm{mg} / \mathrm{ml})\end{array}$ & $\begin{array}{c}\text { Lactic acid } \\
\text { produced } \\
(\%)\end{array}$ & $\begin{array}{c}\text { Optical isomers } \\
\text { of } \\
\text { lactic acid }\end{array}$ \\
\hline N01 & 7.9 & 7.2 & 91.14 & \\
N31 & 9.03 & 7.65 & 84.72 & DL +D \\
N78 & 6.39 & 4.80 & 75.10 & \\
N256 & 8.93 & 8.10 & 90.71 & DL +L \\
N271 & 6.87 & 6.64 & 96.65 & DL + L \\
N53 & 7.9 & 7.88 & 99.74 & \\
ATCC 8042 & 9.47 & 7.88 & 83.21 & \\
Ph01 & 3.0 & 2.93 & 97.96 & \\
Ph37 & 2.32 & 2.25 & 96.98 & \\
Ph45 & 4.57 & 4.28 & 93.65 & \\
Ph133 & 2.04 & 1.91 & 93.63 & \\
Ph155 & 4.13 & 3.49 & 84.50 & \\
TUA Ps033 & 4.2 & 3.38 & 80.48 & \\
TISTR 72 & 3.77 & 3.04 & 80.48 & \\
TISTR 333 & 2.04 & 1.80 & 88.24 & \\
N86 & 4.37 & 3.71 & 84.90 & \\
U01 & 4.20 & 3.71 & 88.33 & \\
C01 & 2.20 & 1.80 & 81.82 & \\
Ph51 & 3.44 & 2.59 & 75.29 & \\
Ph78 & 4.67 & 3.83 & 82.01 & \\
Ph79 & 4.50 & 3.71 & 81.45 & \\
TISTR 395 & 4.57 & 5.40 & 55.50 & \\
TISTR 53 & 9.73 & & & \\
& & 3.71 & & \\
\end{tabular}

groups, some of the catalase negative strains showed the activity of pseudocatalase. Catalase positive strains reduced nitrate to nitrite. A large number of strains grew in medium containing $8 \%$ of alcohol. All the strains were presumed to be microaerophilic or facultatively anaerobic because they grew in stabbed semi-solid agar and cleaved glucose fermentatively. Out of 67 strains, 29 grew with $\mathrm{NaCl}$ at concentrations of more than $18 \%$, and they were regarded as halophilic.

\section{Identification of the isolates}

On the basis of characteristics mentioned above and described in Tables 6 and 7, tetrad-forming, catalase negative bacteria were included in the genus Pediococcus (25), and identified as Pediococcus pentosaceus Mees, Pediococcus acidilactici Lindner, Pediococcus halophilus Mees, and Pediococcus sp. Tetradforming catalase positive bacteria have not been studied enough to date to identify them correctly. Therefore, the present authors include these bacteria tentatively in "Tetracoccus" sp.

Pediococcus pentosaceus Mees Strains: N01, N31, N37, N38, N48, N65, N78, N115, N133, N147, N182, N197, N199, N220, N247, N256, N257, N271, 
Table 6. The general characteristics of species of the genera Pediococcus and "Tetracoccus" based on the strains isolated from Thai fermented foods and related materials.

\begin{tabular}{|c|c|c|c|c|c|}
\hline \multirow[t]{2}{*}{ Characteristics } & 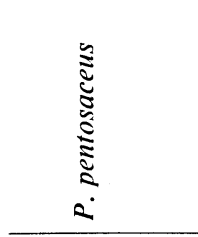 & 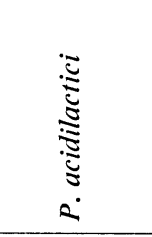 & 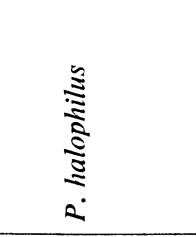 & 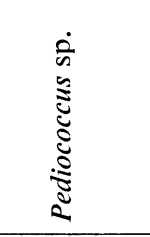 & 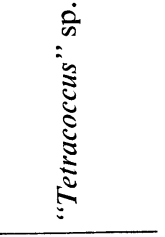 \\
\hline & $\begin{array}{l}\text { No. of } \\
\text { strains } \\
25\end{array}$ & 3 & 29 & 5 & 5 \\
\hline Cell form & - & - & \multicolumn{3}{|l|}{ - $\operatorname{cocci}-$} \\
\hline Cell size $(\mu \mathrm{m})$ & \multicolumn{5}{|c|}{ - $0.4-1.0 \longrightarrow$} \\
\hline Cell arrangement & \multicolumn{5}{|c|}{ occurring singly, in pairs and in tetrads } \\
\hline Gram reaction & + & + & + & + & + \\
\hline Motility & - & - & - & - & - \\
\hline Spore formation & - & - & - & - & - \\
\hline Final $\mathrm{pH}$ in GYP broth & $4.52-4.61$ & $4.60-4.63$ & $4.54-5.11$ & $5.10-5.53$ & $4.87-5.08$ \\
\hline Gas from glucose & - & - & - & - & - \\
\hline Catalase & - & - & - & - & + \\
\hline Pseudocatalase & $+(-10)$ & - & - & - & - \\
\hline Benzidine test & - & - & - & - & + \\
\hline \multicolumn{6}{|l|}{ Reaction in litmus milk: } \\
\hline Reduction & - & - & - & - & - \\
\hline Peptonization & - & - & - & - & - \\
\hline Acid curd & - & - & - & - & $-(+1)$ \\
\hline Hydrolysis of gelatin & - & - & - & - & - \\
\hline Hydrolysis of aesculin & $+(-5)$ & - & - & - & - \\
\hline Hydrolysis of arginine & $-(+\pi 2)$ & + & $+(-14)$ & - & $+(-1)$ \\
\hline Hydrolysis of hippurate & - & - & - & + & - \\
\hline Cleavage of glucose & $+\mathrm{f}$ & $+\mathrm{f}$ & $+\mathrm{f}$ & $+\mathrm{f}$ & $+f$ \\
\hline Nitrate reduction & - & - & - & - & + \\
\hline Reduction of tellurite & NG & NG & NT & NT & NT \\
\hline Indole & - & - & - & - & - \\
\hline Methyl red test & + & + & + & + & + \\
\hline Voges-Proskauer reaction & - & - & - & - & - \\
\hline Utilization of citrate & - & - & NT & NT & - \\
\hline Slime formation & - & - & NT & NT & - \\
\hline Oxidase & - & - & - & - & - \\
\hline \multicolumn{6}{|l|}{ Tolerance to Teepol: } \\
\hline $0.01 \%$ & $+(-1)$ & + & $+(-6)$ & NT & NT \\
\hline $0.02 \%$ & $+(-7)$ & + & $+(-9)$ & NT & NT \\
\hline $0.05 \%$ & $-\left(+1,+{ }^{w} 1\right)$ & - & $-(+4)$ & NT & NT \\
\hline Tolerance to $8 \%$ ethanol & $+(-1)$ & + & + & NT & NT \\
\hline Relation to oxygen & M & M & M & M & $\mathrm{F}$ \\
\hline Growth at $20^{\circ}$ & + & + & + & + & + \\
\hline Growth at $42^{\circ}$ & $+(-1)$ & + & $-\left(+{ }^{\mathrm{w}} 8, \mathrm{NT} 1\right)$ & - & + \\
\hline Growth at $48^{\circ}$ & - & + & NT & NT & NT \\
\hline
\end{tabular}


Table 6. (Continued).

\begin{tabular}{|c|c|c|c|c|c|}
\hline \multirow[t]{2}{*}{ Characteristics } & 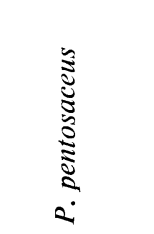 & 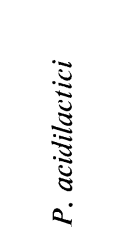 & 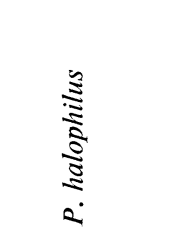 & 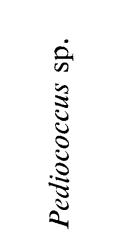 & 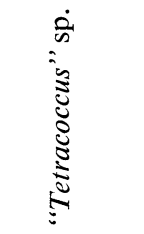 \\
\hline & $\begin{array}{l}\text { No. of } \\
\text { strains } \\
\quad 25\end{array}$ & 3 & 25 & 5 & 5 \\
\hline Growth at $50^{\circ}$ & - & + & NT & NT & NT \\
\hline Optimum temperature & $30-37^{\circ}$ & $30-40^{\circ}$ & $30^{\circ}$ & $20-30^{\circ}$ & $30-37^{\circ}$ \\
\hline Growth at $\mathrm{pH} 3.7$ & - & - & NT & NT & NT \\
\hline Growth at $\mathrm{pH} 4.5$ & + & + & NT & NT & NT \\
\hline Growth at pH 5.0 & + & + & - & - & $+(-1)$ \\
\hline Growth at $\mathrm{pH} 8.2$ & $-(-7)$ & + & + & + & + \\
\hline Growth at $\mathrm{pH} 8.6$ & - & - & + & + & + \\
\hline Growth at $\mathrm{pH} 9.2$ & - & - & $-(-5, \mathrm{NT} 4)$ & + & NT \\
\hline Optimum $\mathrm{pH}$ & $6.7-7.4$ & $6.7-7.4$ & $6.7-8.6$ & $7.4-9.0$ & $6.7-8.2$ \\
\hline \multicolumn{6}{|l|}{ Tolerance to $\mathrm{NaCl}(\%)$ : } \\
\hline Optimum & $0-2$ & $0-2$ & $4-12$ & $0-2$ & $0-4$ \\
\hline Maximum & 10 & 8 & 22 or more & 12 & 18 \\
\hline Halophility & - & - & + & - & - \\
\hline
\end{tabular}

+ , positive; $+^{\mathrm{w}}$, weakly positive; - , negative; NT, not tested.

The numbers in parentheses indicate the numbers of strains showing positive, weakly positive, negative characteristic, or characteristic not tested. NG, no growth; F, fermentative; M, microaerophilic.

N278, N287, N295, N303, ATCC 8081, TUA Pc., and TISTR 335.

The characteristics of these strains agreed with the description of the species $(25,26)$, but variations were found in production of pseudocatalase, hydrolysis of aesculin and arginine, tolerance to Teepol, tolerance to ethanol, growth at $\mathrm{pH}$ 8.2 , growth at $42^{\circ}$, growth at 6 to $8 \% \mathrm{NaCl}$, and acid from sugars. Strain characteristics are shown in Table 8 . The strains in this species were isolated from pla-som (fermented fish), som-fak (fish cake), nham (fermented pork), saikrog-prieo (sour pork sausage and sour beef sausage), phak-gard-dong and phaksian-dong (pickled vegetables), and pieces of food in chicken esophagus.

Pediococcus acidilactici Lindner Strains: N53, N54, and ATCC 8042.

The strains in this species grew even at $50^{\circ}$, hydrolysed arginine, but did not produce acid from maltose. Detailed characteristics are shown in Table 9. These strains were isolated from nham (fermented pork).

Pediococcus halophilus Mees Strains: Ph01, Ph02, Ph08, Ph25, Ph27, Ph37, Ph45, Ph47, Ph58, Ph59, Ph63, Ph65, Ph72, Ph88, Ph93, Ph103, Ph120, Ph122, Ph130, Ph133, Ph134, Ph137, Ph139, Ph144, Ph155, Ph160, TUA Ps033, TISTR 72, and TISTR 333. 
Table 7. Acid formation from carbohydrates of the strains of Pediococcus sp. and "Tetracoccus" sp.

\begin{tabular}{|c|c|c|c|c|c|}
\hline \multirow[t]{2}{*}{ Carbohydrates } & 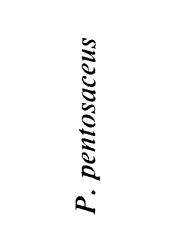 & 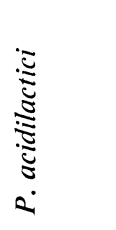 & 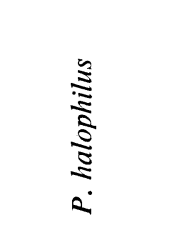 & 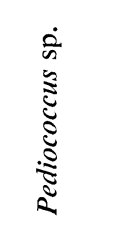 & 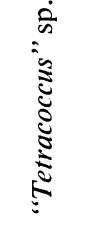 \\
\hline & $\begin{array}{l}\text { No. of } \\
\text { strains } \\
\quad 25\end{array}$ & 3 & 29 & 5 & 5 \\
\hline L-Arabinose & $+(-9)$ & + & $-\left(+3,+{ }^{\mathrm{w}} 1\right)$ & $t^{w}(+1)$ & - \\
\hline D-Ribose & + & + & $+(-2)$ & $+^{\mathrm{w}}(+2)$ & - \\
\hline D-Xylose & $-(+10)$ & + & $+\left(+{ }^{\mathrm{w}} 1,-9\right)$ & $t^{\mathrm{w}}$ & - \\
\hline Rhamnose & $-(+3)$ & $-(+1)$ & - & - & - \\
\hline Fructose & $+\left(+{ }^{\mathrm{w}} 1\right)$ & + & + & + & + \\
\hline Galactose & $+(-2)$ & - & $+\left(+{ }^{w} 2,-8\right)$ & + & $-(+1)$ \\
\hline D-Glucose & + & + & + & + & + \\
\hline Mannose & + & + & + & + & $-(+2)$ \\
\hline$\alpha$ Methyl D-glucoside & - & - & $+(-4)$ & - & - \\
\hline Salicin & $+(-6)$ & $+(-1)$ & $+(-4)$ & + & - \\
\hline Lactose & $-(\mathrm{NT} 1)$ & - & - & $+\left(+{ }^{\mathrm{w}} 1\right)$ & $-(+1)$ \\
\hline Maltose & $+(-1)$ & - & $+(-3)$ & + & $-(+1)$ \\
\hline Sucrose & $-(+10)$ & - & $+\left(+{ }^{w} 2,-2\right)$ & + & $-(+1)$ \\
\hline Trehalose & $+(-6, \mathrm{NT} 1)$ & $-(+1)$ & $+\left(+^{\mathrm{w}} 1,-3\right)$ & + & $+(-1)$ \\
\hline Melezitose & - & - & $-\left(+6,+^{w} 5\right)$ & - & - \\
\hline Raffinose & $-(+4)$ & - & $-\left(+{ }^{\mathrm{w}} 1\right)$ & $-(+2)$ & - \\
\hline Dextrin & - & - & $-(+1)$ & $+^{\mathrm{w}}(+1)$ & - \\
\hline Inulin & $-(+5)$ & - & - & $+w$ & - \\
\hline Starch & - & - & - & - & - \\
\hline Glycerol & - & - & $-\left(+7,+{ }^{\mathrm{w}} 1\right)$ & $+\left(+{ }^{w} 2\right)$ & $+(-1)$ \\
\hline Mannitol & - & - & $-(+11)$ & + & $+(-2)$ \\
\hline Sorbitol & - & - & $-(+12)$ & $-(+1)$ & $+(-2)$ \\
\hline
\end{tabular}

+ , positive; $+^{w}$, weakly positive; - , negative; NT, not tested. The number in parentheses indicate the numbers of strains showing positive, weakly positive, negative characteristic, or characteristic not tested.

The strains in this species were halophilic and grew at $18 \% \mathrm{NaCl}$. They grew at $\mathrm{pH} 8.6$ but not at $\mathrm{pH}$ 5.0. Some strains grew even at $\mathrm{pH}$ 9.2. Variations among the strains were found in hydrolysis of arginine, tolerance to Teepol, and production of acid from sugars. Detailed characteristics are shown in Table 10. The strains in this species were isolated from ching-chung (fermented small fish), hoi-malangpu-dong (pickled mussel), kung-chom (fermented shrimps), nam-budu (fermented fish in liquid form), nam-pla (fish sauce), pla-chom (fermented small fish), pla-paeng-daeng (fermented fish), pla-ra (fermented fish), and tai-pla (fermented fish entrails). 
Table 8. Characteristics of 25 strains

\begin{tabular}{|c|c|c|c|c|c|c|c|c|c|c|c|c|c|c|c|}
\hline Strain & 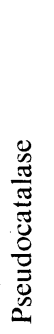 & 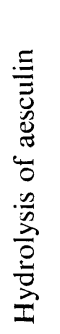 & 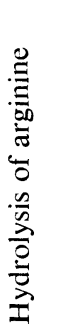 & 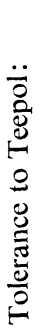 & $\frac{00}{0}$ & $\begin{array}{l}\stackrel{\circ}{\tilde{O}} \\
\stackrel{0}{0}\end{array}$ & $\begin{array}{l}\ddot{0}^{\circ} \\
i \\
0\end{array}$ & 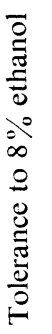 & 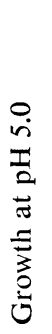 & 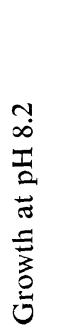 & 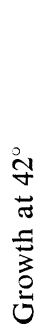 & 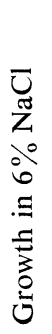 & 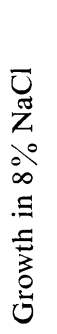 & 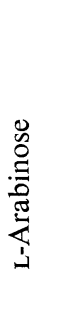 & 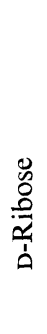 \\
\hline N01 & + & - & $t^{w}$ & & + & - & - & + & + & - & + & + & + & - & + \\
\hline N31 & - & - & - & & + & - & - & + & + & + & + & + & + & - & + \\
\hline N37 & - & - & - & & + & + & - & + & + & + & + & + & + & + & + \\
\hline N38 & + & + & - & & + & + & - & + & + & + & + & + & + & + & + \\
\hline N48 & + & + & - & & + & + & - & + & + & + & + & + & + & - & + \\
\hline N65 & + & + & - & & + & + & - & + & + & + & + & + & + & + & + \\
\hline N78 & + & + & - & & + & - & - & + & + & - & + & + & - & + & + \\
\hline N115 & - & - & - & & + & - & - & + & + & + & + & + & + & - & + \\
\hline N133 & - & + & - & & + & + & - & + & + & + & + & + & - & - & + \\
\hline N147 & - & + & - & & + & + & - & + & + & + & + & + & + & + & + \\
\hline N182 & + & + & - & & + & + & - & + & + & - & + & + & - & - & + \\
\hline N197 & + & + & - & & + & + & - & + & + & + & + & + & + & + & + \\
\hline N199 & + & + & - & & + & + & $+^{w}$ & + & + & + & + & + & + & + & + \\
\hline N220 & - & + & - & & + & + & - & + & + & - & + & + & + & + & + \\
\hline $\mathrm{N} 247$ & + & + & - & & + & + & - & + & + & + & + & + & + & + & + \\
\hline N256 & - & + & - & & + & + & - & + & + & + & + & + & + & + & + \\
\hline $\mathrm{N} 257$ & - & + & - & & + & + & - & + & + & + & + & + & + & + & + \\
\hline $\mathrm{N} 271$ & - & - & - & & - & - & - & - & + & - & - & + & + & - & + \\
\hline N278 & + & + & - & & + & + & - & + & + & + & + & + & + & + & + \\
\hline N287 & - & + & - & & + & - & - & + & + & + & + & + & + & - & + \\
\hline N295 & + & + & - & & + & + & + & + & + & + & + & + & + & - & + \\
\hline N303 & + & + & - & & + & + & - & + & + & + & + & + & + & + & + \\
\hline ATCC 8081 & + & + & - & & + & + & - & + & + & - & + & + & + & + & + \\
\hline TUA Pc. & + & + & $+\infty$ & & + & + & - & + & + & + & + & - & - & + & + \\
\hline TISTR 335 & + & + & - & & + & - & - & + & + & - & + & - & - & + & + \\
\hline
\end{tabular}

+ , positive; $+^{w}$, weakly positive; - , negative; NT, not tested.

Pediococcus sp. Strains: N86, U01, U03, U20, and TISTR 394.

The strains studied grew at $\mathrm{pH} 9.2$ but not at $\mathrm{pH} 5.0$, and they hydrolysed hippurate. They were not halophilic. Variation among the strains was found in production of acid from sugars. Out of 5 strains, 4 strains produced acid from lactose. Detailed characteristics are shown in Table 11. The characteristics of the isolates were almost identical with those of " $P$. urinae-equi" TISTR 394. However, this species is not on the Approved Lists of Bacterial Names, 1980 (11) and further characterization of this species has not been reported to date. Therefore, the present authors retain the naming of the isolates. The strains were 
of Pediococcus pentosaceus.

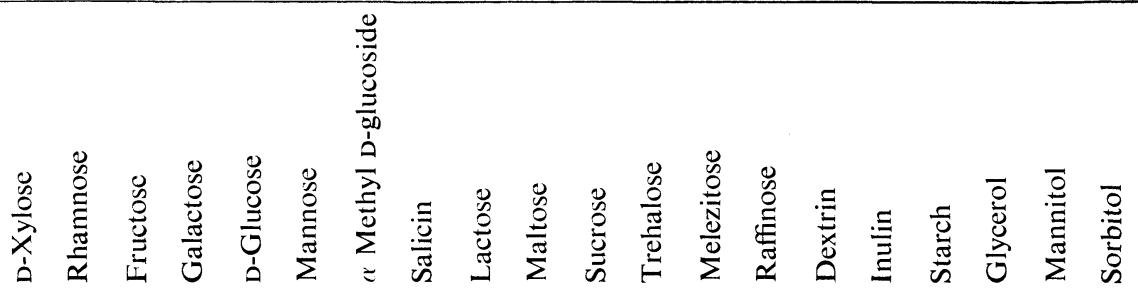

\begin{tabular}{|c|c|c|c|c|c|c|c|c|c|c|c|c|c|c|c|c|c|c|c|}
\hline- & - & + & + & + & + & - & - & - & + & + & + & - & - & - & + & - & - & - & - \\
\hline- & - & $+w$ & - & + & + & - & - & - & + & + & - & - & - & - & + & - & - & - & - \\
\hline+ & + & + & + & + & + & - & + & - & + & - & - & - & - & - & - & - & - & - & - \\
\hline+ & - & + & + & + & + & - & + & - & + & - & + & - & - & - & - & - & - & - & - \\
\hline- & - & + & + & + & + & - & + & - & + & + & + & - & - & - & - & - & - & - & - \\
\hline+ & - & + & + & + & + & - & + & - & + & + & + & - & + & - & - & - & - & - & - \\
\hline- & - & + & + & + & + & - & + & - & + & + & + & - & + & - & - & - & - & - & - \\
\hline- & - & + & + & + & + & - & + & - & + & - & + & - & - & - & - & - & - & - & - \\
\hline- & - & + & + & + & + & - & + & - & + & - & - & - & - & - & - & - & - & - & - \\
\hline- & + & + & + & + & + & - & $\div$ & - & + & - & + & - & - & - & - & - & - & - & - \\
\hline- & - & + & + & + & + & - & + & - & + & - & + & - & - & - & - & - & - & - & - \\
\hline+ & - & $\div$ & + & + & + & - & + & - & + & - & + & - & - & - & - & - & - & - & - \\
\hline+ & - & -+ & + & + & + & - & - & - & + & - & + & - & - & - & - & - & - & - & - \\
\hline- & - & + & + & + & + & - & + & - & + & + & + & - & + & - & + & - & - & - & - \\
\hline- & - & + & + & + & + & - & + & - & + & - & + & - & - & - & - & - & - & - & - \\
\hline- & - & + & + & + & + & - & + & - & + & - & - & - & - & - & - & - & - & - & - \\
\hline+ & - & + & + & + & + & - & + & - & + & + & + & - & + & - & - & - & - & - & - \\
\hline- & - & + & - & + & + & - & - & - & - & - & - & - & - & - & - & - & - & - & - \\
\hline+ & - & + & + & + & + & - & + & - & + & - & - & - & - & - & - & - & - & - & - \\
\hline- & - & + & + & + & + & - & - & - & + & - & + & - & - & - & - & - & - & - & - \\
\hline- & + & + & + & + & + & - & + & - & + & + & + & - & - & - & + & - & - & - & - \\
\hline+ & - & + & + & + & + & - & + & - & + & + & + & - & - & - & + & - & - & - & - \\
\hline+ & - & $\div$ & + & + & + & - & - & NT & + & - & NT & - & - & - & - & - & - & - & - \\
\hline+ & - & + & + & + & + & - & + & - & + & + & + & - & - & - & - & - & - & - & - \\
\hline- & - & + & + & + & + & - & + & - & + & - & + & - & - & - & - & - & - & - & - \\
\hline
\end{tabular}

isolated from phak-gard-dong (pickled vegetables), horse urine and rabbit dung.

“Tetracoccus" sp. Strains: CO1, Ph51, Ph78, Ph79, and TISTR 395.

The strains studied were catalase positive and reduce nitrate to nitrite. They were halotolerant, growing at a concentration of $18 \%$ of $\mathrm{NaCl}$, but not requiring $\mathrm{NaCl}$ for growth. Variations among the strains were found in the curdling of litmus milk, hydrolysis of arginine, and production of acid from sugars. Detailed characteristics are shown in Table 12. The characteristics of the isolates were identical to those of "Tetracoccus soyae" TISTR 395 which was originally isolated from soy mash by UeNO and OMATA (27). However, this species is not on the 
Table 9. Characteristics of 3 strains

\begin{tabular}{|c|c|c|c|c|c|c|c|c|c|c|c|c|c|c|c|}
\hline Strain & 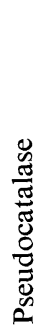 & 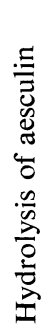 & 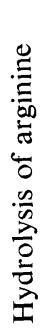 & 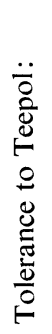 & $\frac{00}{0}$ & $\begin{array}{l}\stackrel{0}{O} \\
\stackrel{O}{0}\end{array}$ & $\begin{array}{l}\stackrel{0}{0} \\
\stackrel{0}{0} \\
\dot{0}\end{array}$ & 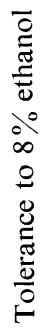 & 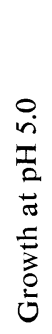 & 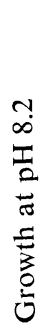 & 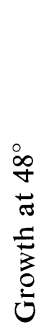 & 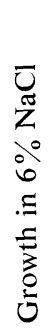 & 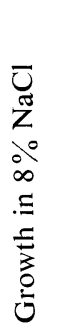 & 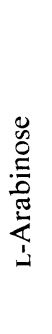 & 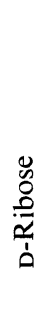 \\
\hline N53 & - & - & + & & + & + & - & + & + & + & + & + & $t^{w}$ & + & + \\
\hline N54 & - & - & + & & + & + & - & + & + & + & + & + & $+^{\mathrm{w}}$ & + & + \\
\hline ATCC 8042 & - & 一 & + & & + & + & - & + & + & + & + & - & - & + & + \\
\hline
\end{tabular}

+ , positive; ${ }^{+}{ }^{\mathrm{w}}$, weakly positive; - , negative

Approved Lists of Bacterial Names, 1980 (11), and it has not been characterized to date. Therefore, the present authors include these strains tentatively in the genus "Tetracoccus", and retain the naming of the strains.

\section{DISCUSSION}

Pediococcus strains are widely distributed in the fermented foods in Thailand, and the species are source specific. The halophilic strains were frequently isolated from the fermented products of fish, and the non-halophilic ones found in products of meat and vegetables, as shown in Table 1. This may be due to the concentration of $\mathrm{NaCl}$ in the foods. Some products of fermented fish seem to be similar to "shiokara" in Japan. On the contrary, P. pentosaceus strains were found in pla-som (fermented fish) which is produced under a low concentration of $\mathrm{NaCl}$.

Recently, isolation of Pediococcus strains from nam-pla (fish sauce in Thailand) (7) was reported, and microflora in fermented foods in Asian countries have attracted interest of microbiologists (7). Further studies will make clear the function of the microorganisms involved.

As mentioned above, the catalase positive tetrad-forming cocci have not been differentiated from related genera at present. Taxonomic study of this group of bacteria is essential, and chemotaxonomic comparison would be useful for the differentiation of "Tetracoccus" from related genera. The strains of "Tetracoccus" have been isolated from shoyu mash (27), and they are presumed to play roles in making the shoyu $(4,5)$. In this study, such bacteria were also isolated from nam-budu (fermented fish in liquid form), pla-chom (fermented small fish), and kapi (fish or shrimp paste).

The authors with to thank Prof. Dr. K. Komagata, Institute of Applied Microbiology, University of Tokyo, Tokyo, Japan, for editing the manuscript; Prof. Dr. M. Kozaki, Dr. T. Toyoda and Dr. S. Okada, Laboratory of Applied Microbiology, Tokyo University of Agricul- 
of Pediococcus acidilactici.

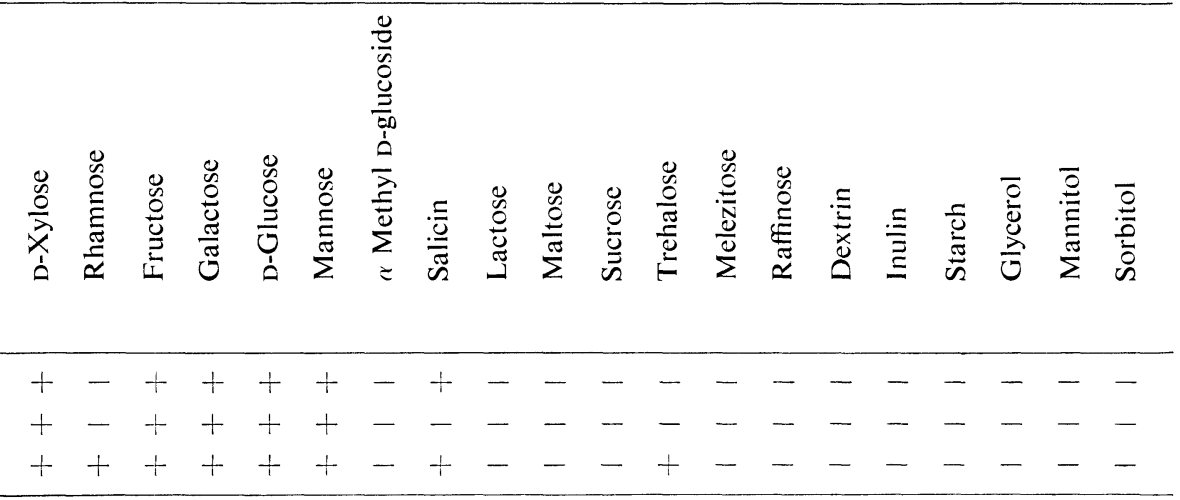

ture, Tokyo, Japan, for advice about methods, analysis of optical isomers of lactic acid, and supplying materials. We are also grateful to Miss Poonsook Atthasumpunna and Mrs. Wanchern Daengsubha, TISTR, Bangkhen, Bangkok 10900, Thailand, for providing the cultures.

This study was in part supported by the co-operation MIRCEN Research Grant (UNEP/ UNESCO). 
Table 10. Characteristics of 29 strains

\begin{tabular}{|c|c|c|c|c|c|c|c|c|c|c|c|c|c|c|c|}
\hline Strain & $\begin{array}{l}0 \\
\frac{0}{0} \\
\frac{\pi}{\pi} \\
\frac{\pi}{0} \\
0 \\
0 \\
0 \\
0 \\
0 \\
0\end{array}$ & 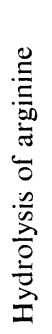 & 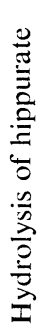 & 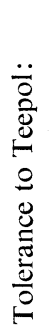 & $\frac{0^{0}}{0}$ & $\begin{array}{l}\stackrel{0}{0} \\
\stackrel{0}{0} \\
\stackrel{0}{0}\end{array}$ & $\begin{array}{l}0 \\
i \\
0 \\
0\end{array}$ & 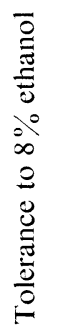 & 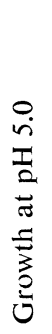 & 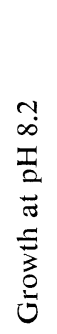 & 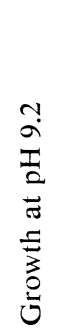 & 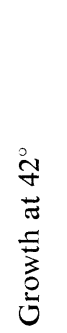 & $\begin{array}{l}\bar{U} \\
\tilde{Z} \\
00 \\
0 \\
\Xi \\
\Xi \\
\vdots \\
\vdots \\
0 \\
0 \\
0\end{array}$ & 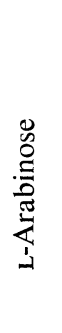 & 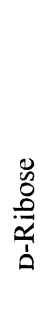 \\
\hline $\mathrm{Ph01}$ & - & - & - & & + & + & - & + & - & + & + & - & + & - & + \\
\hline $\mathrm{Ph} 02$ & - & - & - & & - & - & - & + & - & + & - & - & + & - & - \\
\hline Ph08 & - & + & - & & + & + & - & + & - & + & + & - & + & - & + \\
\hline $\mathrm{Ph} 25$ & - & - & - & & + & + & - & + & - & + & + & - & + & + & + \\
\hline $\mathrm{Ph} 27$ & - & - & - & & + & + & - & + & - & + & + & - & + & - & + \\
\hline Ph37 & - & - & - & & + & + & - & + & - & + & + & - & + & + & + \\
\hline $\mathrm{Ph} 45$ & - & - & - & & + & + & + & + & - & + & + & - & + & - & + \\
\hline $\mathrm{Ph} 47$ & - & + & - & & + & + & + & + & - & + & + & - & + & - & + \\
\hline Ph58 & - & - & - & & + & + & - & + & - & - & - & - & + & - & + \\
\hline Ph59 & - & - & - & & + & + & - & + & - & + & + & - & + & - & + \\
\hline Ph63 & - & + & - & & $T$ & + & - & + & - & + & + & $+{ }^{\mathrm{w}}$ & + & - & + \\
\hline Ph65 & - & - & - & & - & + & + & + & - & + & + & $t^{\mathrm{w}}$ & + & - & + \\
\hline $\mathrm{Ph} 72$ & - & - & - & & - & - & - & + & - & - & + & - & + & - & + \\
\hline Ph88 & - & + & - & & - & - & - & + & - & + & NT & $+^{\mathrm{w}}$ & + & - & + \\
\hline Ph93 & - & - & - & & $\div$ & - & - & + & - & + & NT & - & + & - & + \\
\hline Ph103 & - & $\div$ & - & & - & - & - & + & - & + & NT & $t^{\mathrm{w}}$ & + & - & + \\
\hline $\mathrm{Ph} 120$ & - & + & - & & - & + & - & $\div$ & - & + & + & $+^{\pi}$ & + & + & + \\
\hline $\mathrm{Ph} 122$ & - & $\div$ & - & & - & + & - & + & - & + & + & - & + & - & + \\
\hline Ph130 & - & + & - & & - & + & - & + & - & $\div$ & NT & - & $\div$ & - & + \\
\hline Ph133 & - & $\div$ & - & & - & - & - & + & - & + & - & - & + & - & + \\
\hline Ph134 & - & + & - & & - & $\div$ & - & $\div$ & - & + & + & - & + & - & + \\
\hline Ph137 & - & - & - & & - & + & - & + & - & + & + & - & + & $+^{w}$ & + \\
\hline Ph139 & - & + & - & & - & - & - & + & - & + & - & - & + & - & + \\
\hline Ph144 & - & + & - & & + & + & + & + & - & + & + & $+w$ & + & - & + \\
\hline Ph155 & - & - & - & & $T$ & + & - & + & - & + & + & - & + & - & + \\
\hline $\mathrm{Ph} 160$ & - & $T$ & - & & - & - & - & + & - & + & - & - & + & - & + \\
\hline TUA Ps033 & - & $t$ & - & & + & + & - & + & - & + & + & $+w$ & + & - & + \\
\hline TISTR 72 & - & - & - & & + & + & - & + & - & + & + & $+w$ & + & - & - \\
\hline TISTR 333 & - & + & - & & + & - & - & + & - & + & + & NT & + & - & + \\
\hline
\end{tabular}


of Pediococcus halophilus.

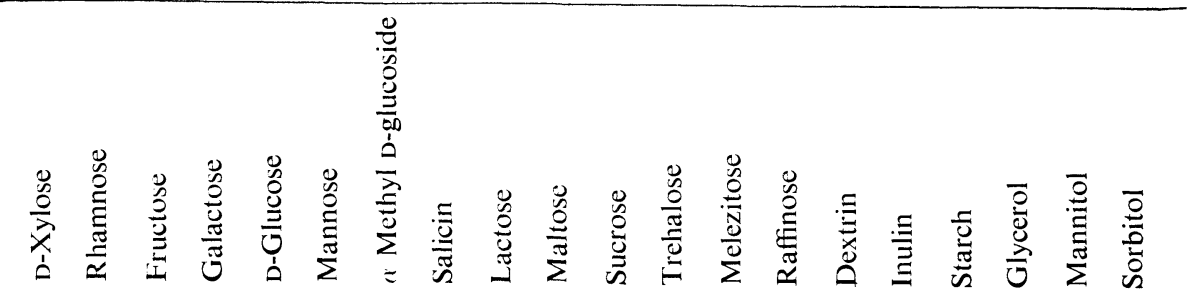

\begin{tabular}{|c|c|c|c|c|c|c|c|c|c|c|c|c|c|c|c|c|c|c|c|}
\hline- & - & + & - & + & + & - & + & - & - & $+w$ & + & - & - & - & - & - & - & - & - \\
\hline+ & - & $\div$ & $\div$ & + & + & + & - & - & - & + & + & + & - & - & - & - & - & + & - \\
\hline+ & - & + & + & + & + & $T$ & + & - & $\cdots$ & + & $\div$ & + & - & - & - & - & - & - & - \\
\hline$T$ & - & + & ${ }^{\mathrm{w}}$ & + & + & + & + & - & - & + & + & $+w$ & - & - & - & - & - & - & - \\
\hline+ & - & - & $T$ & + & + & $T$ & + & - & + & + & $\div$ & - & - & - & - & - & + & + & + \\
\hline+ & - & - & - & + & + & + & + & - & - & + & $\div$ & - & $+^{w}$ & - & - & - & - & + & + \\
\hline+ & - & $T$ & - & $T$ & + & - & $T$ & - & - & + & + & $T^{\mathrm{w}}$ & - & - & - & - & - & + & + \\
\hline- & - & - & - & + & $\div$ & - & - & - & - & $\div$ & - & $\div$ & - & - & - & - & - & + & - \\
\hline+ & - & + & $\ldots^{\mathrm{w}}$ & + & + & $T$ & $T$ & - & $\cdots$ & - & $\div$ & + & - & - & - & - & + & - & - \\
\hline+ & - & - & - & + & + & - & + & - & - & $\div$ & $\div$ & - & - & - & - & - & $+\mathrm{w}$ & - & - \\
\hline- & - & - & - & + & + & $T$ & $T$ & - & - & + & $\div$ & - & - & - & - & - & - & - & + \\
\hline- & - & - & - & - & + & $\div$ & - & - & - & + & $T$ & - & - & - & - & - & - & - & + \\
\hline- & - & - & - & - & - & - & - & - & - & - & - & - & - & - & - & - & - & - & - \\
\hline- & - & - & - & $T$ & $T$ & - & - & - & - & $\cdots$ & - & - & - & - & - & - & - & - & - \\
\hline- & - & - & - & $\therefore$ & $\div$ & - & - & - & + & - & + & - & - & - & - & - & + & $\div$ & - \\
\hline- & - & - & - & - & + & $T$ & - & - & - & + & $\rightarrow^{\mathrm{v}}$ & - & - & - & - & - & - & + & + \\
\hline- & - & - & - & 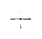 & $T$ & - & - & - & - & + & + & $\ldots *$ & - & - & - & - & $\div$ & - & $\div$ \\
\hline+ & - & - & -. & - & + & $T$ & + & - & - & $T$ & $\div$ & $\cdots$ & $\cdots$ & - & - & - & + & + & $\div$ \\
\hline- & - & - & - & -- & - & - & $\therefore$ & - & - & + & - & - $"$ & - & - & - & - & + & - & - \\
\hline$+\pi$ & - & - & - & $\div$ & + & - & $\cdots$ & - & - & + & - & - & - & - & - & - & - & + & + \\
\hline+ & - & - & - & -- & $T$ & - & - & - & $\ldots$ & - & - & - & - & - & --- & - & - & - & - \\
\hline+ & - & - & $T$ & + & $\div$ & -- & - & $\cdots$ & $\cdots$ & $\div$ & F- & $\ldots w$ & - & - & -- & - & - & - & - \\
\hline- & - & - & - & - & + & - & - & - & - & $T$ & + & $\therefore$ & - & - & - & - & - & - & - \\
\hline+ & - & + & + & $\div$ & - & - & + & - & $T$ & - & + & - & -- & - & - & - & $\div$ & - & + \\
\hline- & - & + & + & + & $\div$ & + & - & - & - & $\therefore$ & + & - & - & - & - & - & - & - & + \\
\hline- & - & + & - & + & + & - & + & - & - & $T$ & + & - & - & - & - & - & - & - & + \\
\hline- & - & + & + & + & $\div$ & - & + & - & - & $-" x$ & - & - & - & - & - & - & - & - & - \\
\hline- & - & $T$ & - & $\div$ & $\div$ & $\cdots$ & $\cdots$ & - & - & - & - & - & $\ldots$ & $\div$ & - & - & - & + & - \\
\hline- & - & - & - & - & $T$ & - & - & - & - & - & - & -- & - & - & - & - & - & + & - \\
\hline
\end{tabular}


Table 11. Characteristics of 5 strains

\begin{tabular}{|c|c|c|c|c|c|c|c|c|c|c|c|}
\hline Strain & 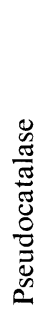 & 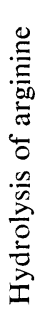 & 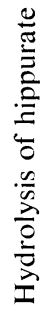 & 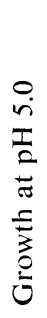 & 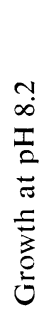 & 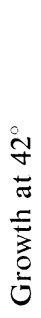 & 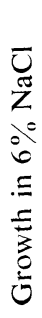 & 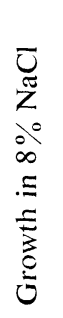 & 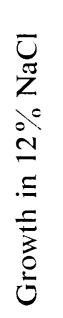 & $\frac{\mathscr{E}}{\stackrel{0}{0}}$ & $\begin{array}{l}0 \\
0 \\
0 \\
\frac{0}{2} \\
\dot{1}\end{array}$ \\
\hline N86 & - & - & + & - & + & - & + & + & + & + & $+w$ \\
\hline U01 & - & - & $\div$ & - & + & - & + & + & + & $+w^{w}$ & + \\
\hline U03 & - & - & + & - & + & - & + & $+n$ & - & $+^{-}$ & + \\
\hline U20 & - & - & + & - & + & - & + & + & $+{ }^{w}$ & $+{ }^{*}$ & $t^{w}$ \\
\hline TISTR 394 & - & - & + & - & + & - & + & $+{ }^{w}$ & - & $+w$ & $+w$ \\
\hline
\end{tabular}

+ , positive; $+{ }^{w}$, weakly positive; - , negative.

Table 12. Characteristics of 5 strains

\begin{tabular}{|c|c|c|c|c|c|c|c|c|c|c|c|c|c|}
\hline Strain & $\frac{\ddot{E}}{\frac{\tilde{J}}{\tilde{N}}}$ & 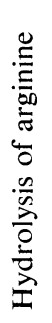 & 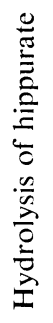 & 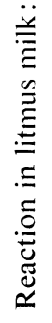 & 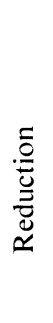 & 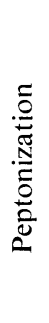 & $\begin{array}{l}\bar{Z} \\
\stackrel{0}{0} \\
\stackrel{0}{0}\end{array}$ & 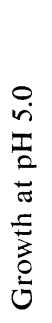 & 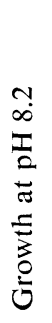 & 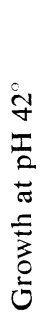 & $\begin{array}{l}\bar{U} \\
z \\
z \\
00 \\
\infty \\
\Xi \\
\Xi \\
\vdots \\
0 \\
0 \\
0\end{array}$ & 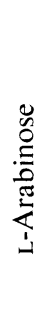 & $\begin{array}{l}u \\
0 \\
\frac{0}{0} \\
\frac{0}{0} \\
0\end{array}$ \\
\hline $\mathrm{C} 01$ & + & - & - & & - & - & + & - & + & + & + & - & - \\
\hline Ph51 & + & + & - & & - & - & - & + & + & + & + & - & - \\
\hline $\mathrm{Ph} 78$ & + & + & - & & - & - & - & + & + & + & + & - & - \\
\hline Ph79 & + & + & - & & - & - & - & + & + & + & + & - & - \\
\hline TISTR 395 & + & + & - & & - & - & - & + & + & + & + & - & - \\
\hline
\end{tabular}

+ , positive; - , negative. 
of Pediococcus sp.

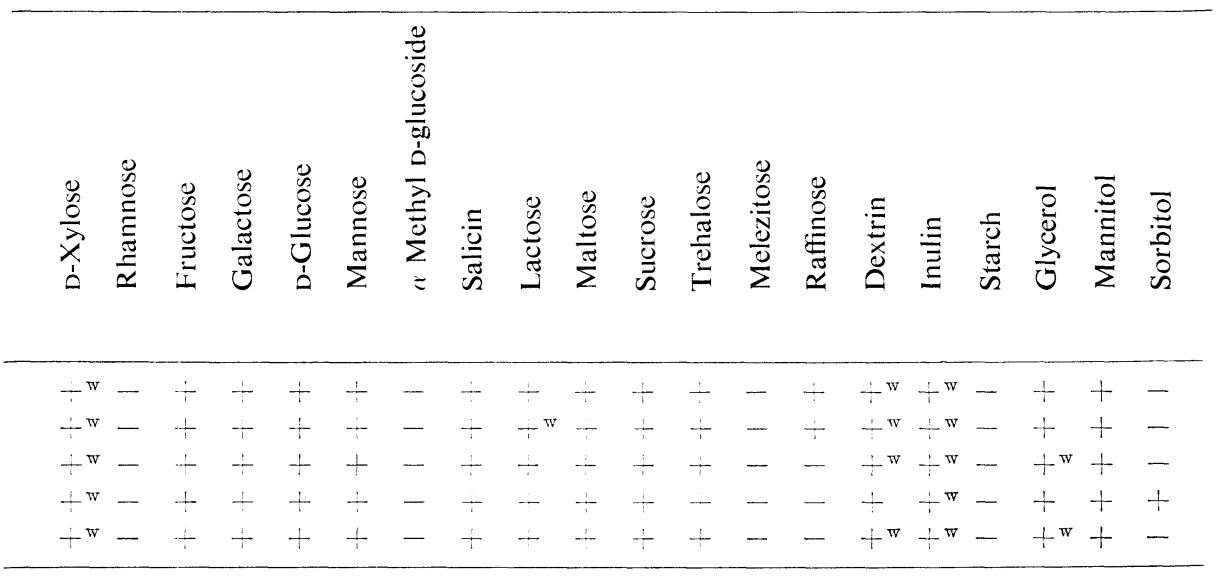

of "Tetracoccus" sp.

\begin{tabular}{|c|c|c|c|c|c|c|c|c|c|c|c|c|c|c|c|c|c|c|c|}
\hline 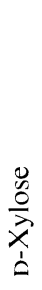 & 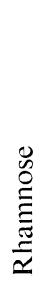 & 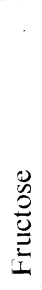 & 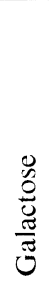 & 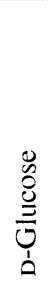 & 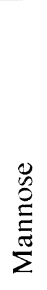 & 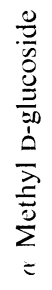 & 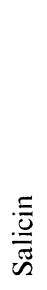 & 苞 & $\frac{\mathscr{D}}{\stackrel{B}{E}}$ & 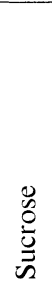 & $\begin{array}{l}\frac{0}{0} \\
\frac{0}{0} \\
\frac{\pi}{D}\end{array}$ & $\frac{\stackrel{0}{0}}{\frac{\stackrel{0}{N}}{2}}$ & 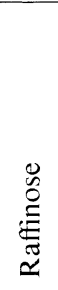 & 志 & $\stackrel{\Xi}{\Xi}$ & $\begin{array}{l}\overline{\bar{d}} \\
\text { 离 }\end{array}$ & $\begin{array}{l}\overline{0} \\
\stackrel{0}{0} \\
\frac{0}{0}\end{array}$ & 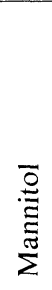 & $\begin{array}{l}\overline{0} \\
: \overline{0} \\
\overline{0} \\
\tilde{\omega}\end{array}$ \\
\hline- & - & + & - & + & + & - & - & + & $\div$ & + & - & - & - & - & - & - & + & - & - \\
\hline- & - & + & - & + & - & - & - & - & - & - & $\perp$ & - & - & - & - & - & - & - & - \\
\hline- & - & + & - & + & - & - & - & - & - & - & + & - & - & - & - & - & + & + & + \\
\hline- & - & $\div$ & - & + & - & - & - & - & - & - & + & - & - & - & - & - & + & + & + \\
\hline- & - & + & - & + & + & - & - & - & - & - & + & - & - & - & - & - & + & + & + \\
\hline
\end{tabular}




\section{REFERENCES}

1) K. Kitahara and A. Nakagawa, J. Gen. Appl. Microbiol., 4, 21 (1958).

2) C. S. Pederson, Bacteriol. Rev., 13, 225 (1949).

3) J. L. Etchells, R. N. Costilow, T. E. Anderson and T. A. Bell, Appl. Microbiol., 12. 523 (1974).

4) K. Sakaguchi, Bull. Agric. Chem. Soc. Jpn., 22, 353 (1958).

5) T. Sugimori and H. Joze, Abstract in Food Sci. Technol., 3(9), Abstract 9T445 (1971).

6) W. Susukida, F. Masuko and T. Matsuo, J. Ferment. Technol., 39, 1 (1961).

7) National Research Council of Thailand, Report on Thai Traditional Fermented Food Research Project, Phase I, 41 (1981-1982).

8) C. A. Orillo and C. S. Pederson, Appl. Microbiol., 16, 1669 (1968).

9) M. Sundhagul, W. Daengsubha and P. Suyanandana, Thai. J. Agric. Sci., 8, 205 (1975).

10) J. M. Appleton, V. F. McGowan and V. B. D. Skerman, Microorganisms and Man. World Data Center (MIRCEN), Department of Microbiology, University of Queensland, St. Lucia 4067, Brisbane, Australia (1978-80), p. 1.

11) V. B. D. Skerman, V. McGowan and P. H. A. SNeath (ed.), Int. J. Syst. Bacteriol., 30, 225 (1980).

12) Society of American Bacteriologists, Manual of Microbiological Methods., McGraw-Hill Book Co., Inc., New York (1957), p. 13.

13) R. Whittenbury, J. Gen. Microbiol, 32, 375 (1963).

14) T. Gibson and V. Abd-el-Malek, J. Dairy. Res., 14, 35 (1945).

15) E. A. Dawes, D. J. McGill and M. Midglex, Analysis of fermentation products, In Methods in Microbiology, 6A, ed. by J. R. Norris and D. W. Ribbons, Academic Press, New York (1971), p. 53.

16) Laboratory Manual, Laboratory of Applied Microbiology, Department of Agricultural Chemistry, Tokyo University of Agriculture, Tokyo (1980).

17) S. Okada, T. Toyoda and M. Kozaki, Agric. Biol. Chem., 42, 1781 (1978).

18) E. A. Felton, J. B. Evans and C. F. Niven, J. Bacteriol., 65, 481 (1953),

19) R. H. Deibel and J. B. Evans, J. Bacteriol. 79, 356 (1960).

20) M. Gemmell and W. Hodgkiss, J. Gen. Microbiol., 35, 519 (1964).

21) M. J. Thornley, J. Appl. Bacteriol., 23, 37 (1960).

22) A. G. BAIRd-PARker, Method for classifying staphylococci and micrococci. In Identification methods for microbiologists. Part A. ed. by B. M. GibBs and F. A. Skinner, Academic Press, New York (1966), p. 59.

23) V.B. D. Skerman. Abstracts of Microbiological Methods., The Wiley-Interscience, A Division of John Wiley and Sons, New York (1969).

24) N. Kovac, Nature, 178, 703 (1956).

25) K. Kitahara, In Bergey's Manual of Determinative Bacteriology, 8th ed., ed. by R. E. Buchanan and N. E. Grbbons, The Williams and Wilkins Co., Baltimore (1974), p. 513.

26) A. Nakagawa and K. Kitahara, J. Gen. Appl. Microbiol., 5. 95 (1959).

27) T. Ueno and S. Omata, J. Ferment. Technol., 39, 360 (1961). 